\title{
Case of acute optic nerve compression caused by tuberculum sellae meningioma with optic canal involvement
}

This article was published in the following Dove Press journal:

Clinical Ophthalmology

30 April 2012

Number of times this article has been viewed

\author{
Yuzhu Chai' \\ Hiroko Yamazaki' \\ Akihide Kondo ${ }^{2}$ \\ Toshiyuki Oshitari ${ }^{3}$ \\ Shuichi Yamamoto ${ }^{3}$ \\ 'Department of Ophthalmology, \\ Kohnodai Hospital, National Center \\ for Global Health and Medicine, \\ Chiba, ${ }^{2}$ Department of Neurosurgery, \\ Juntendo University, School \\ of Medicine, Tokyo, ${ }^{3}$ Department \\ of Ophthalmology and Visual Science, \\ Chiba University Graduate School \\ of Medicine, Chiba, Japan
}

\begin{abstract}
We present detailed ophthalmic findings in a case of tuberculum sellae meningioma with acute visual symptoms due to optic canal involvement. A 62-year-old Japanese woman reported a 1-week history of headaches and blurred vision in her left eye. Her visual acuity was 0.3 in the left eye with no ophthalmoscopic abnormalities. A relative afferent pupillary defect and inferior temporal field defect were found in the left eye. Pattern visual evoked potentials were undetectable in the left eye. Enhanced magnetic resonance imaging showed a $9 \mathrm{~mm}$ intracranial lesion around the left optic nerve anterior to the chiasm. She was diagnosed with granulomatous inflammation because of the increased cell counts and protein concentration in the cerebrospinal fluid. She was treated with steroid pulse therapy, and her visual acuity and visual field defect improved to normal in 3 weeks. However, 16 months after the onset, she suffered from headaches again and had a complete loss of vision in her left eye. There was no response to steroid pulse therapy. Enhanced magnetic resonance imaging revealed that the lesion had extended into the left optic canal, and emergency tumor removal surgery was carried out. The histopathological diagnosis was meningioma. One month after the surgery, her left visual acuity improved to 1.2, and her visual field was almost normal. Pattern visual evoked potentials were present but had a prolonged $\mathrm{P}_{100}$ latency of $170 \mathrm{~ms}$. A thinning of the ganglion cell complex was detected by optical coherence tomography. Ophthalmologists should be aware that a small tuberculum sellae meningioma can cause acute visual symptoms due to optic canal involvement. Early consultation with a neurosurgeon is necessary. Visual evoked potentials and optical coherence tomography are sensitive and helpful in following patients with optic nerve compression.
\end{abstract}

Keywords: optic nerve compression, tuberculum sellae meningioma, optic canal involvement, pattern visual evoked potentials, optical coherence tomography

\section{Introduction}

Meningiomas are the most common slow-growing tumors of the central nervous system. Tuberculum sellae (TS) meningiomas, a member of a group called "parasellar meningiomas," grow in the subchiasmal area that can compress the optic nerves. Patients with TS meningiomas usually present with gradual monocular or binocular visual loss. Neurosurgeons have reported that TS meningiomas have a high tendency to extend into the optic canal regardless of their size. ${ }^{1-5}$ Mahmoud et al reported the tumor extended into the optic canal in $67 \%$ of 58 patients with TS meningiomas. ${ }^{2}$ Sade and Lee reported that optic canal involvement was $77.4 \%$ in 31 patients with TS meningiomas. ${ }^{3}$ Although optic canal involvement is common in TS meningiomas and may cause acute visual symptoms, a search of Medline with the words "TS
Correspondence: Yuzhu Chai Department of Ophthalmology, Kohnodai Hospital, National Center for Global Health and Medicine, I-7-I Kohnodai Ichikawa City, Chiba 27285I6, Japan Tel +8147372350 I

Fax +81473721858

Email chai_yuzhujp@yahoo.co.jp 
meningiomas" and "optic canal involvement" did not extract any publications of cases presenting with acute visual symptoms with detailed ophthalmic findings.

We present detailed ophthalmic findings in a case of TS meningioma with acute visual symptoms due to optic canal involvement. In addition to visual acuity and visual field examinations, pattern visual evoked potentials (VEPs) and optical coherence tomography (OCT) were performed.

\section{Case report}

A healthy 62-year-old Japanese woman complained of a 1 -week history of frontal headaches. The headache moved to the left supra-orbital region and she noted blurred vision in the left eye. She visited the neurologic department of Kohnodai Hospital (Chiba, Japan) on March 9, 2010. The results of general physical examination were unremarkable. She was suspected of having retrobulbar optic neuritis and was hospitalized immediately. However, enhanced magnetic resonance imaging (MRI) showed a $9 \mathrm{~mm}$ heterogeneous intracranial lesion attached to the TS around the left optic nerve anterior to the chiasm (Figure 1A-C). Examination of the cerebrospinal fluid showed an increase of the cell counts $(171 / \mathrm{mL}$ mononuclear cells 162 , polynuclear cells 9 , normal range: $<45 / \mathrm{mL}$ ) and protein concentration $(61 \mathrm{mg} / \mathrm{dL}$, normal range: $10-40 \mathrm{mg} / \mathrm{dL})$.
These findings led to a tentative diagnosis of granulomatous inflammation with optic nerve compression. She was treated with steroid pulse therapy, and then referred to the ophthalmologic department for neuro-ophthalmic examinations on March 11, 2010.

Her best-corrected visual acuity (BCVA) was 1.0 in the right eye and 0.3 in the left eye, and she had a relative afferent pupillary defect in the left eye. The results of ophthalmoscopic examinations were normal (Figure 2A and B). Static perimetry 30-2 with the Humphrey field analyzer (HFAII 745; Carl Zeiss AG, Oberkochen, Germany) showed an inferior temporal field defect in the left eye (Figure 2C and D). The pattern VEPs elicited by transient and steadystate stimuli to the left eye were undetectable (Figure 3). She was diagnosed with optic nerve compression. Three weeks after the steroid pulse treatment, her BCVA improved to 1.2, and the field defect disappeared. At the 1-year follow-up examination, her BCVA remained in 1.2, and the visual field was almost normal in the left eye without any treatment (Figure 2E). A thinning of the ganglion cell complex (GCC) was detected by a spectral domain OCT (Figure 4).

On July 23, 2011, she began suffering from headaches again, and she noted a complete loss of vision in her left eye. She was immediately referred to the neurosurgical department. She was treated with steroid pulse therapy again,
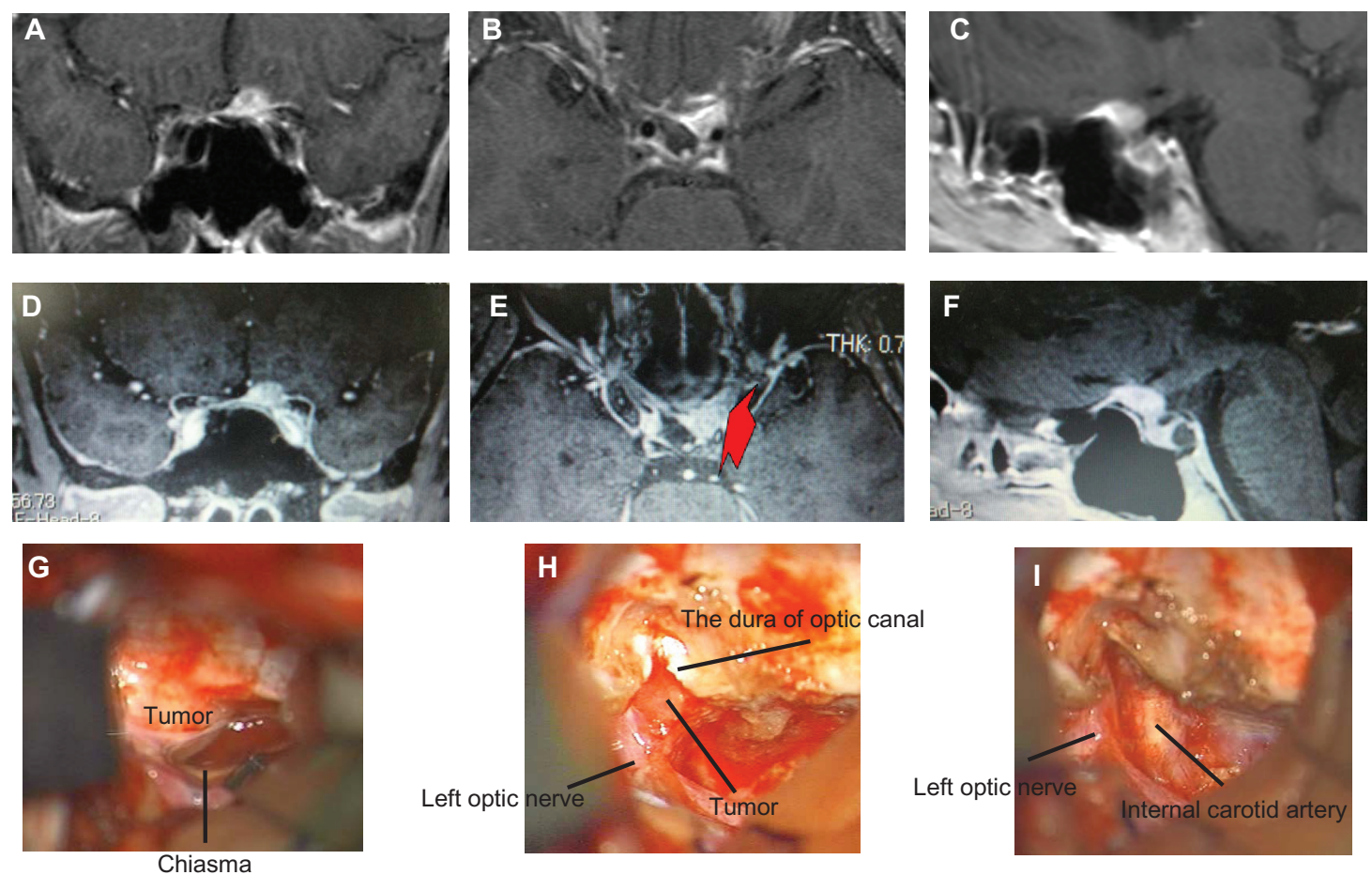

Figure I Enhanced magnetic resonance imaging and operative views. (A-C) At the onset, a 9 mm heterogeneous intracranial lesion attached to the tuberculum sellae can be seen. The mass was close to the left optic nerve anterior to the chiasm. (D-F) Preoperatively, thin sliced enhanced magnetic resonance imaging showed the lesion had extended into the left optic canal (red arrow). (G-I) The tumor was successfully removed including the intracranial lesion by opening the optic canal. 

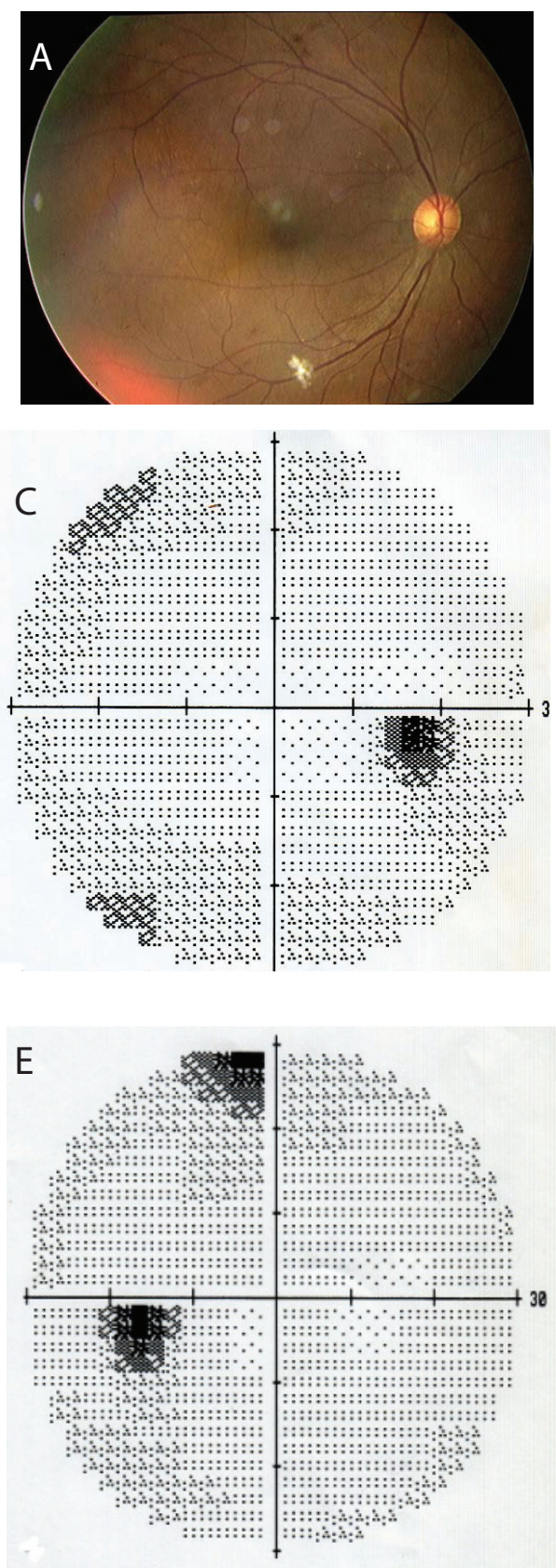
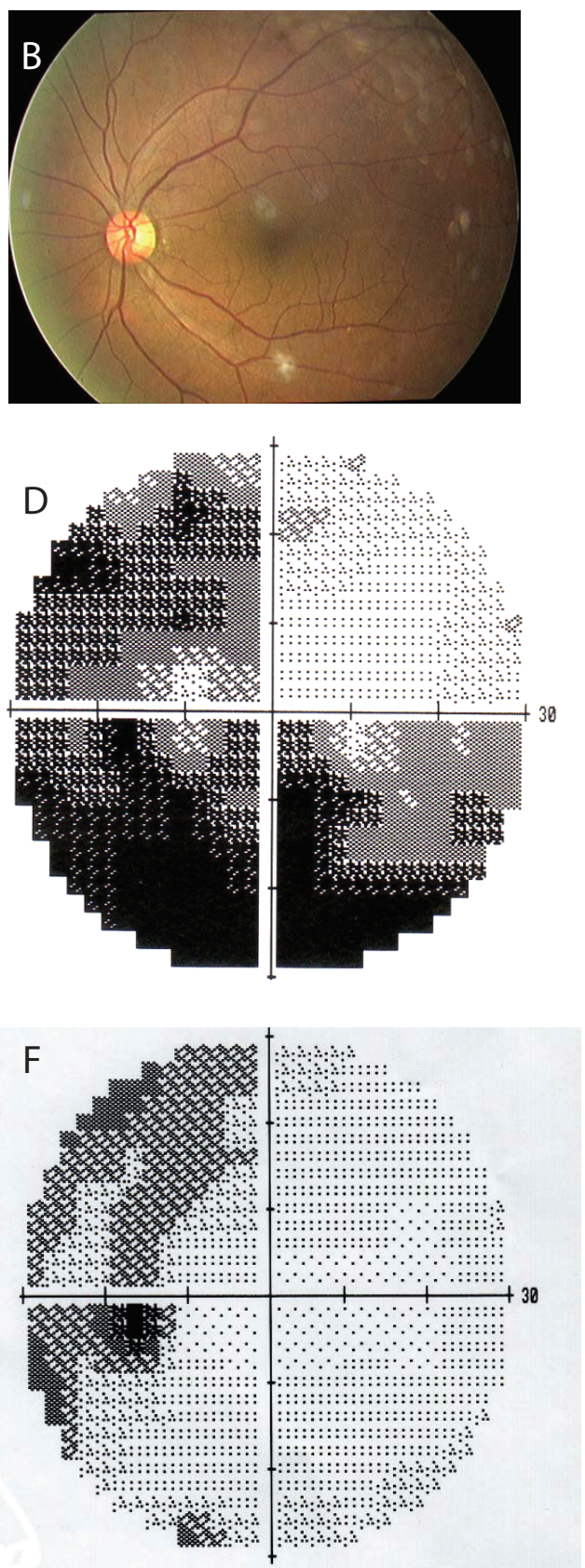

Figure 2 Fundus photograph and results of Humphrey static perimetry. (A and $\mathbf{B}$ ) At the onset, fundus photograph showed that the retina and disc were normal. (C and D) At the onset, Humphrey static perimetry showed inferior temporal field defect in the left eye (30-2 strategy MD - 17.57 dB), and normal field in the right eye. (E) One year after the onset, Humphrey static perimetry showed the visual field was almost normal (30-2 strategy MD -2.35 dB). (F) One month after surgery, Humphrey static perimetry showed a mild temporal hemianopia (30-2 strategy MD $-3.19 \mathrm{~dB})$.

but there was no improvement. The visual acuity remained at no light perception and there was no direct light reflex in the left eye. Thin sliced enhanced MRI revealed that the intracranial lesion had extended into her left optic canal, even though the size of the main mass was almost the same as earlier (Figure 1D-F). Emergency surgery was carried out on July 29, 2011. A hemi-interhemispheric approach was used, and the tumor was successfully removed (Simpson grade 2) including the intracranial lesion by opening the optic canal (Figure 1G-I). A diagnosis of meningothelial meningioma was made by histopathological examination of the removed tissue.

One month after surgery, her BCVA improved to 1.2, and a mild temporal hemianopia was detected in the left eye (Figure 2F). The pattern VEPs were present but had a prolonged $\mathrm{P}_{100}$ latency of $170 \mathrm{~ms}$ (Figure 3 ). OCT showed that the GCC was thinner than the preoperative thickness (Figure 4). At 3 months, all of the findings remained the same. 
At the onset
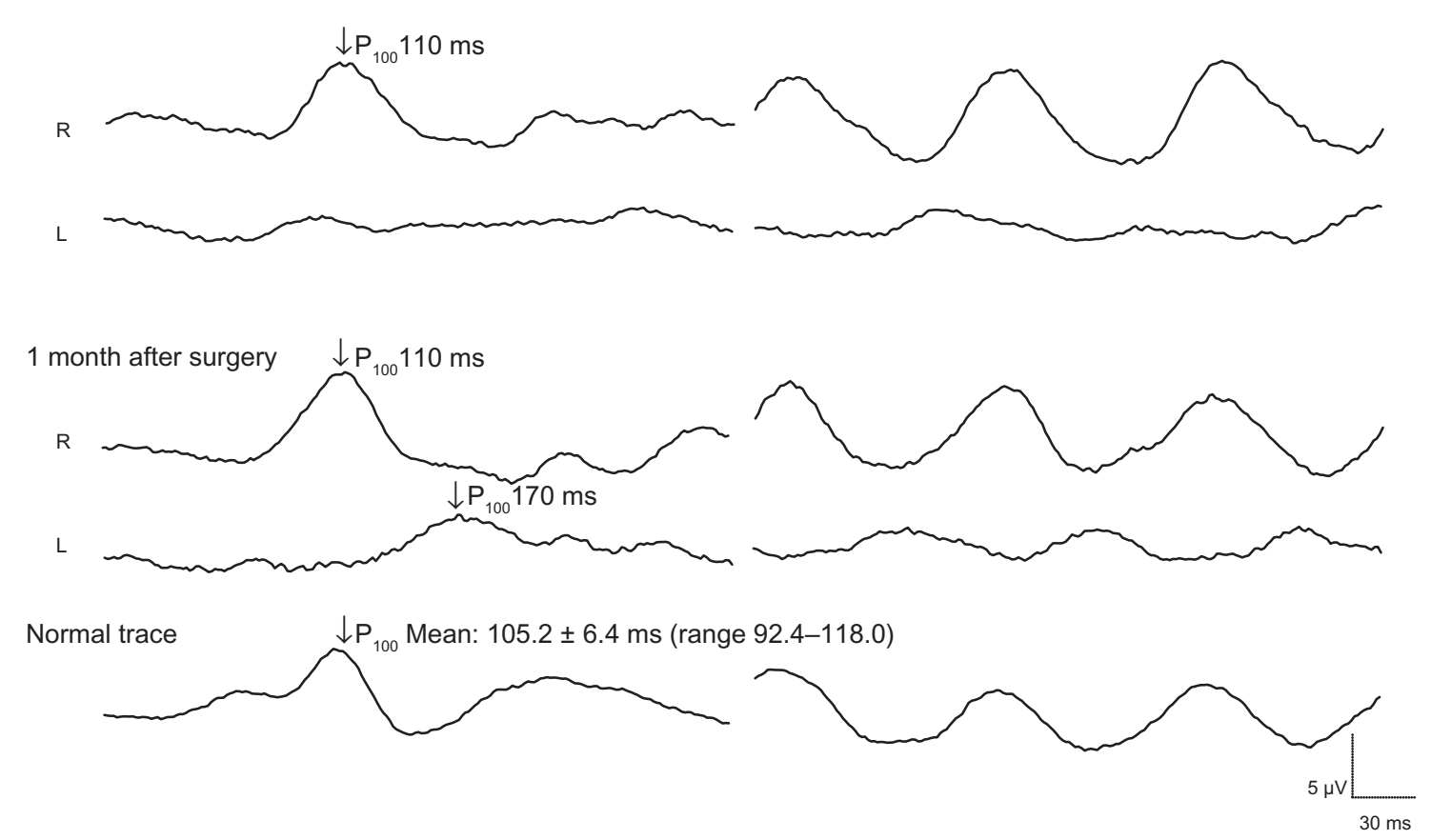

Figure 3 Pattern visual evoked potentials.

Notes: At the onset, the pattern visual evoked potentials elicited by transient and steady-state stimuli to the left eye were undetectable. One month after surgery, pattern visual evoked potentials were present but had a prolonged $\mathrm{P}_{100}$ latency of $170 \mathrm{~ms}$ in the left eye (mean: $105.2 \pm 6.4 \mathrm{~ms}$; normal range: 92.4 to II $8.0 \mathrm{~ms}$ ).

Abbreviation: VEP, visual evoked potentials.

\section{Discussion}

The sudden onset of headaches and blurred vision, the normal fundus, the undetectable pattern VEPs, and the excellent response to steroid therapy could lead ophthalmologists to a misdiagnosis of optic neuritis. There have been several reports that stated that patients with intracranial lesions could present with acute optic neuropathy mimicking optic neuritis, and any atypical features should warrant neuroimaging. ${ }^{6-9}$ For our case, the older age and inferior temporal field defect were atypical features of optic neuritis but suggestive of optic nerve compression. An enhanced MRI would have been helpful in ruling out an intracranial lesion.

At the onset, we diagnosed the intracranial lesion as granulomatous inflammation because of the increased cell

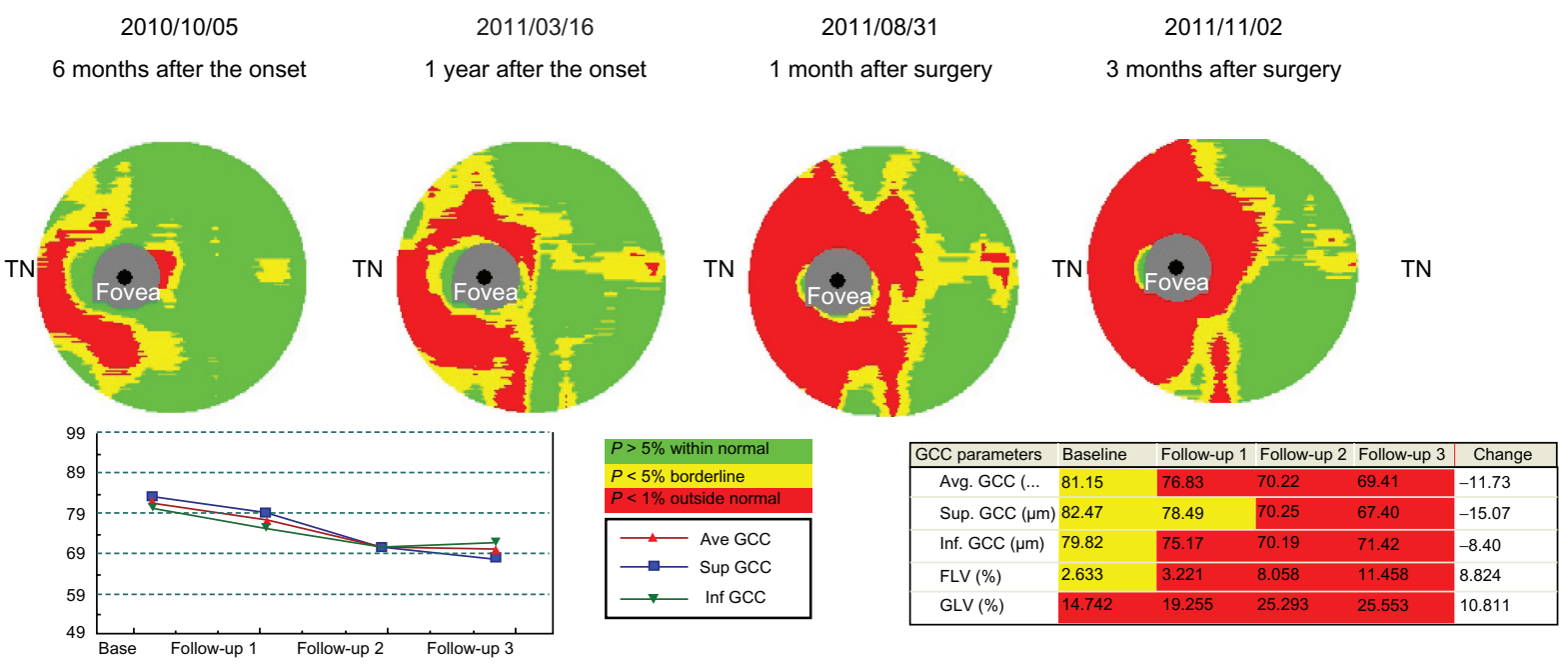

Figure 4 Optical coherence tomography.

Notes: Preoperatively, a thinning of the ganglion cell complex was detected by optical coherence tomography even while her visual function was stable. After surgery, the ganglion cell complex area was thinner than the preoperative thickness, but became stable during the 3 months of follow-up.

Abbreviations: GCC, ganglion cell complex; FLV, focal loss volume; GLV, global loss volume. 
counts and protein concentration in the cerebrospinal fluid. However, there were no other systemic abnormalities, and there was no reduction of the size of the lesion after steroid therapy. We also considered the possibility of a meningioma, but because the lesion was very small and her visual function was stable after steroid therapy, the patient did not wish to have an operation. Strikingly, she completely lost her left vision suddenly 16 months after the onset. Enhanced MRI revealed that the intracranial lesion had extended into her left optic canal, and emergency tumor removal by opening the optic canal was successful in restoring her left vision.

Optic canal involvement is common in TS meningiomas and may cause acute visual loss, which is well-known by neurosurgeons. ${ }^{1-5}$ Ophthalmologists should be aware that a small TS meningioma can cause acute visual symptoms due to optic canal involvement. Early consultation with a neurosurgeon is necessary.

One month after surgery, pattern VEPs were present but had a prolonged $\mathrm{P}_{100}$ latency of $170 \mathrm{~ms}$ although her visual acuity and visual field had improved dramatically to almost normal. Our case showed that electrophysiological examinations were sensitive enough to detect subclinical optic nerve damage, as has been reported. ${ }^{10-12}$

Recent studies have shown that OCT can be useful in quantifying neuronal loss in patients with optic nerve compression. Monteiro et al reported that in patients with temporal hemianopia from chiasmal compression, the OCTmeasured macular thickness was topographically related to the decrease of visual field sensitivity. ${ }^{13}$ Moon et al reported that the GCC thickness could be a useful prognostic indicator in the preoperative assessment of chiasmal compression. ${ }^{14}$ Our case had a thinning of the GCC even while her visual function was stable preoperatively. After surgery, the GCC was thinner than the preoperative thickness, but became stable during the 3 months of follow-up. The OCT findings may have suggested continuous and irreversible death of ganglion cells due to the subclinical optic nerve compression preoperatively. Further studies are needed to find out how OCT can be used in the assessment of optic nerve compression.

\section{Conclusion}

We reported a case of TS meningioma presenting with acute visual symptoms due to optic canal involvement with detailed ophthalmic findings. Ophthalmologists should be aware that a small TS meningioma can cause acute visual symptoms due to optic canal involvement. Early consultation with a neurosurgeon is necessary. VEPs and OCT are sensitive and helpful in following patients with optic nerve compression.

\section{Acknowledgment}

We thank Professor Duco Hamasaki of the Bascom Palmer Eye Institute of the University of Miami, FL for editing this manuscript.

\section{Disclosure}

No conflicting relationship exists for any author.

\section{References}

1. Hayhurst C, Teo C. Tuberculum sella meningioma. Otolaryngol Clin North Am. 2011;44(4):953-963.

2. Mahmoud M, Nader R, Al-Mefty O. Optic canal involvement in tuberculum sellae meningiomas: influence on approach, recurrence, and visual recovery. Neurosurgery. 2010;67(3):108-118.

3. Sade B, Lee JH. High incidence of optic canal involvement in tuberculum sellae meningiomas: rationale for aggressive skull base approach. Surg Neurol. 2009;72(2):118-123.

4. Margalit NS, Lesser JB, Moche J, Sen C. Meningiomas involving the optic nerve: technical aspects and outcomes for a series of 50 patients. Neurosurgery. 2003;53(3):523-523.

5. Arai H, Sato K, Okuda O, et al. Transcranial transsphenoidal approach for tuberculum sellae meningiomas. Acta Neurochir (Wien). 2000;142(7):751-756.

6. Anderson D, Khalil M. Meningioma and the ophthalmologist. A review of 80 cases. Ophthalmology. 1981;88(10):1004-1009.

7. Anderson D, Khalil MK. Meningioma and the ophthalmologist: diagnostic pitfalls. Can J Ophthalmol. 1981;16(1):10-15.

8. Lee AG, Lin DJ, Kaufman M, Golnik KC, Vaphiades MS, Eggenberger E. Atypical features prompting neuroimaging in acute optic neuropathy in adults. Can J Ophthalmol. 2000;35(6):325-330.

9. Lin MC, Bee YS, Sheu SJ. A suprasellar meningioma simulating atypical retrobulbar optic neuritis. J Chin Med Assoc. 2003;66(11):689-692.

10. Halliday AM, Halliday E, Kriss A, McDonald WI, Mushin J. The pattern-evoked potential in compression of the anterior visual pathways. Brain. 1976;99(2):357-374.

11. Lenton L, Stark DJ. Electrophysiological assessment of compressive lesions of anterior visual pathways. Trans Ophthalmol Soc N Z. 1981;33:87-90.

12. Holder GE. The effects of chiasmal compression on the pattern visual evoked potential. Electroencephalogr Clin Neurophysiol. 1978;45(2):278-280.

13. Monteiro ML, Costa-Cunha LV, Cunha LP, Malta RF. Correlation between macular and retinal nerve fibre layer Fourier-domain OCT measurements and visual field loss in chiasmal compression. Eye (Lond). 2010;24(8):1382-1390.

14. Moon CH, Hwang SC, Kim BT, Ohn YH, Park TK. Visual prognostic value of optical coherence tomography and photopic negative response in chiasmal compression. Invest Ophthalmol Vis Sci. 2011;52(11):8527-8533. 


\section{Publish your work in this journal}

Clinical Ophthalmology is an international, peer-reviewed journal covering all subspecialties within ophthalmology. Key topics include: Optometry; Visual science; Pharmacology and drug therapy in eye diseases; Basic Sciences; Primary and Secondary eye care; Patient Safety and Quality of Care Improvements. This journal is indexed on
PubMed Central and CAS, and is the official journal of The Society of Clinical Ophthalmology (SCO). The manuscript management system is completely online and includes a very quick and fair peer-review system, which is all easy to use. Visit http://www.dovepress.com/ testimonials.php to read real quotes from published authors. 